\title{
A Study of Grammatical Code Switching Among EFL University Students
}

\section{Gholamreza Abbasian, Maryam Heydarpour Meymeh, Azadeh Zarbafian gabbasian@gmail.com}

Assistant Professor, Imam Ali University and Islamic Azad University, South Tehran Branch, Tehran, Iran mmeymeh@yahoo.com (corresponding author)

Faculty Member, Shahid Beheshti University of Medical Sciences, Faculty of Paramedical Sciences, English Language Department azadehzarbafian@yahoo.com

\section{ABSTRACT}

Islamic Azad University, South Tehran Branch, English Language Department

Code switching is a widely observed but less studied phenomenon, especially in multilingual and multicultural communities. So, the present study investigated the status of grammatical code switching among Iranian EFL university students. Also, the role of the teacher in managing the code switching was investigated, too. Two classes including 96 participants from two different universities were observed carefully and the required data were collected. Analyses of the data revealed varying nature of code switching in both settings. Moreover, the obtained frequencies revealed the fact that among the four types of 'trigger words' only 'proper nouns' and discourse marker 'OK' remarkably were responsible for code switching in one setting, while 'lexical transfer' and also the discourse marker 'OK' lead to code switch in another. Meanwhile, four functions for code switching were determined, which included providing equivalents for the key word, showing humor, inspiring learners, and explaining the required assignments, as teacher's role in dealing with code switching .

\section{Keywords}

Code Switching, EFL Classroom, Interference and Interaction

\section{Academic Discipline}

Education

\section{Council for Innovative Research}

\section{Peer Review Research Publishing System}

\section{Journal: Journal of Social Sciences Research}

Vol. 8, No.1

jssreditor.cir@gmail.com

www.jssronline.com 


\section{INTRODUCTION}

One of the important issues with which EFL/ESL researchers are concerned is "Code Switching". Many researches (Greggio, S. and Gil, G. (2007), Schweers, (1999), Tang, (2002), Clyne, (1980) and observations on bilinguals depict that they change languages in the middle of a conversation, while transferring from one topic to the other one can be regarded as a more or less conscious state. According to Javier and Marcos (1989), the process of keeping language separately and bringing into contact when it is needed is defined as "Code Switching" phenomena. Nunan and Carter (2001) refer to code switching as "a phenomenon of switching from one language to another in the same discourse" (p. 275).

According to Richards and Schmidt (2002), code switching happens when a person goes from one language to another. This shift occurs when the person uses a language during a conversation and the other person continues the speech in another language in the middle of his speech. A similar proposal was offered by Crystal (1987) based on which code or language, switching happens when a person who is bilingual substitutes two languages during his/her discourse with an alternate bilingual individual. In specific circumstances, individuals utilize a code to pass on their message which is characterized as any arrangement of signs utilized for communicating something specific or as an equivalent word for language variety. Crystal (1987) characterizes code switching as the method of blending two codes or languages without rolling out an improvement in the theme of discussion. It is then evident that this method presupposes a certain level of useful capability in both languages which causes the event of shift between the two languages while taking after the linguistic, grammatical and phonetic standards of each of the languages. It can likewise be portrayed as the act of moving here and there and then here again between two languages or registers of the same language, additionally called "codemixing" or" inferences". This sensation happens significantly more frequently in speaking than in writing. Berthold, Mangubhai and Batorowicz (1997) contended that interference may be regarded as the transference of components of a language to an alternate at different levels including phonological, syntactic, lexical and orthographical. Jacobson (1983) depicts code switching as a method for vocabulary choice in both languages of correspondence. Cook (2001) notes that code switching ought to be emphatically stayed away from the classroom, because of its impedance which may cause mistakes on speaker's side.

There are distinctive manifestations of code switching. The position of code switching may fluctuate as it can be toward the end or start of the sentence. Observing familiar bilingual speakers uncovered that they lead to intersentential code switching, implying that the language switch is carried out at sentence limits. This is otherwise called mechanical switching that is unconscious. The inverse term can be categorized as intrasentential code switching. Otherwise called code changing transferring that starts with one language then onto the next, in which the variation is carried out amidst a sentence deliberately with no interferences, stops or hesitations that allude to the blending (Lipski, 1985).

Code switching is one of the main primary instruments in enhancing learning and teaching styles and helping learners to better grasp thoughts and express their considerations (Schweers, 1999; Tang, 2002; Greggio and Gil, 2007). Skiba (1997) contended that code switching can be considered as an indication of poor capability in one language, and the second language is utilized to handle the issues they have in speaking with the first language.

\section{PERSPECTIVES ON CODE SWITCHING}

Code switching has been habitually concentrated on from alternate points of view. Semantically, as per Myers-Scotton (1993), code variation is linguistic by nature and very relies on upon the bilingual's familiarity with the two languages. From a sociolinguistical point of view, it is concerned with the way individuals use it as a talk enhancer in their day by day discourse. Gem (1987), for instance, suggests conceivable sociolinguistic purposes behind utilizing code switching, for example, the speaker's powerlessness to convey what needs, convey herself in one language as a consequence of exhaustion or passionate state, her yearning to show solidarity with an exceptional gathering, and the propensity to impart his or her demeanor to an audience. Alluding to the six capacities of code switching including repetition, quotation, addressee specification, message qualification, interjection, personification, Gumperz (1982) considers it as an uncommon talk method which bilinguals generally use for distinctive purposes amid their interchanges.

In Code-Switching Lessons, we demonstrate best practices to set out the red pen and utilization of effective methods contrastive examination and code switching - for showing Standard English punctuation in etymologically assorted classrooms. You'll find that some of what look like lapses in your children's written work are really the examples of their vernacular language (Riehl, (2005). In other words, learners frequently compose much as it is talked in rhythms, and examples learners have utilized at home and as a part of their neighborhoods from conception through the minute they venture into your class. Code-Switching Lessons shows how to discover these casual examples in children's composition and utilization contrastive examination to analyze group English and formal scholastic English, helping learners expand on their current language structure information to include new learning. When the teacher has furnished the learners with unequivocal consciousness of the contrasts in the middle of casual and formal English, proper methodologies for leading them to code-switch are demonstrated - to pick the language style to fit the setting, the time, place, crowd, and reason they have for conveying (Riehl, (2005).

The latest progresses in psycholinguistic study have been concerned with code-switching as a characteristic result of the association of the bilingual's two languages. For example, Vogt (1954, p. 368) considers code switching as "a mental sensation whose reasons are clearly extralinguistic that is, it doesn't happen only as a consequence of language utilization yet by the mental methods occurring in the bilingual's mind". Besides, Clyne (1991) alludes to "psycho-linguistically motivated" code switching advanced by trigger words which suggest that it is not sociolinguistic or syntactic utilization of language, yet the cognitive techniques occurring in the speakers' mind that incite variation of language. Clyne (1991, p.193) believes that trigger words will be "words at the convergence of two language frameworks, which, thusly, may 
cause speakers to lose their etymological orientation and proceed with the sentence in the other language." They lead to variation as the two language present comparable lexical items. Such lexical items give data both about cognitive representation methods of bilingualism and about bilingual language transforming (Riehl, 2005).

The speculation of triggering, presented by Clyne $(1980,2003)$, is concerned with the encouraging pretended by words which have a tendency to make code switching smoother. Clyne (2003) believes that trigger words comprise of such things as "formal people, "lexical exchange", "bilingual homophones", and things or places." Discourse markers are additionally embedded under the name of bilingual homophones. The premise of present study is additionally on the grouping put forward by Clyne (2003).

\section{A DISCUSSION ON THE USE OF CODE SWITCHING IN LANGUAGE CLASSES}

Many scholars (Gumperz, (1982), Jacobson, (1983), Schweers,(1999), Skiba (1997), Cook, (2001) who are agreed to utilize informative systems in the language teaching environment, contradict any type of local language utilization amid classroom direction. In opposition to this, supporters of the utilization of local language as code switching propose that it might be a compelling method in different viewpoints. Taking after the thoughts of these two gatherings, some powerless and solid sides of the utilization of code switching in remote language classroom settings will be considered as a discriminating viewpoint.

An alternate point to consider is that the capability of the educator in primary language of learners likewise assumes an imperative part, if positive commitments of code switching are expected. A further exchange is advanced by Eldridge, as he proposes "the learners have no guarantee that their audience will share knowledge of their mother tongue" (1996, p.309). This idea is related to the connection of learners with local speakers of the target language, as common understandability may not be conceivable if the learner switches his language amid the correspondence.

In supporting the presence of code switching in classes, Skiba (1997) proposes that in situations where code switching is utilized because of a powerlessness of declaration, it serves for congruity in discourse as opposed to showing obstruction in language. In this way, code switching stands to be a supporting component in correspondence of data and in social association; and accordingly fills for the needs in a way that is utilized as an instrument for transference of significance. Moreover, the capacities of the instructor's code switching remain as strong clarifications for the solid sides of the marvel. All of these lead to the thought that the utilization of code switching scaffold from known to obscure and may be considered as a vital component in language showing when utilized effectively.

\section{SIGNIFICANCE OF THE STUDY}

Code exchanging has been viewed by a few researchers as a marker of poor capability in one language. The other language is utilized to adjust for the challenges that the learners have in corresponding with the first language (Skiba, 1997). Ellis (1984) considers the negative impact of educators' utilization of code exchanging in second language classrooms as denying learners of their privileges of second language accomplishments. Alluding to the impedance part of code exchanging and its error- proneness nature, Cook (2001) hassles that code exchanging ought to be firmly evaded in the classroom. Code exchanging has been concentrated on alternate points of view; linguistically, socio-linguistically and psycho-linguistically in different settings; both bilingual and multilingual.

Referring to what is mentioned before, it is clear that studies in code switching (CS) have been concerned with its event in bilingual and multilingual social settings (Gumperz, 1982; Cheng and Bultler, 1989; Kachru, 1989). Few researches have been led on code switching in foreign language classrooms particularly in Iranian EFL settings (Yaqubi and Doqaruni, 2009). It is important to mention that English language instruction in Iran begins at secondary schools, took after by preuniversity English, General English, lastly Specialized English courses at tertiary level. Inadequate introduction to English language makes learners and educators more willing to code switch amid classroom cooperations. Subsequently, because of the developing use of code switching in Iranian EFL classrooms, including especial English courses and general English courses and its part in educator understudy associations and in light of the lack of examination done here at tertiary instruction in Iran, this study was directed to fill the gaps.

Therefore, the following research questions were raised in this study:

Q1. What are the effective factors causing code switching in Iranian EFL university students?

Q2. What is the instructor's role in managing the code switching?

\section{METHOD}

\section{DESIGN OF THE STUDY}

The present study was adhered to be a qualitative one since the gathered data was based on observations and notes of researchers themselves.

\section{PARTICIPANTS}

In order to conduct this research, the researchers invited 96 students to participate in this experiment. The students were freshmen students at the university majoring physiotherapy in Shahid Beheshti University of Medical Sciences and Industrial Engineering in Islamic Azad University South Tehran Branch. The participants were aged from nineteen to twenty one. The classes were held once a week for three hours. Two MA holders (PhD candidates) were teaching classes. 


\section{DATA COLLECTION}

The researchers observed the teaching-learning process for fifteen sessions. The observers made comprehensive field notes (i.e. systematic and comprehensive description of all classroom events) that consisted of number of students, teaching and learning activities in which code switching happened in class, types of code switching happened, verbal and nonverbal interaction, etc.

\section{RESULTS}

After collecting the required data, all the data were analyzed based on the Clyne's classification. It is worth mentioning that each example is accompanied by transcription the sentences in Farsi and they are presented in italics. And the bold letters are indicators of the code switching functions. Clyne's (1991) classification of 'trigger words' includes proper nouns, lexical transfer, bilingual homophones and discourse markers. The researchers obtained the following results by analyzing the notes and observations in each class.

Proper nouns' are considered to be those words which do not have "translation equivalent in the other language but are used in both languages in a phonologically identical form" (Riehl, 2005, p. 1947). An example regarding proper nouns is put forward.

\subsection{Trigger words in Shahid Beheshti University}

T: Have you ever heard that someone had a brain death?

S: Yeah. Our neighbor had a brain death last week after his surgery.

T: Really? (marge maqzi az beyn raftene daemie hame faliat haye asai maqz mibashad)

(Brain death is a permanent loss of all essential activities of the brain)

In this example, 'Brain death' which is regarded as a proper noun, made the teacher to code switch from English to Farsi and also the students were motivated to switch to Farsi. This is the only proper noun that was found in observations. There was no example regarding the 'lexical transfer', or 'bilingual homophones'.

The other one refers to the word 'OK' in the following example.

T: bahse emrooz dabare Intention tremor ast (Today's discussion is about Intention tremor). OK, let's talk about different ways in which causes this tremor.

$\mathrm{S}$ : Age is one of causes of this tremor.

Here the discourse marker 'OK' prompted the teacher to switch from Persian to English. One reason may be that these markers have been completely integrated into the recipient language system through borrowing from the contact language (Riehl, 2005). However, due to linguistic differences between English and Persian languages, the only discourse marker that triggers code switching was the word 'OK'.

\subsection{Trigger words in Azad University}

Analysis of the observations in this class displayed no instances of code switching related to bilingual homophones or proper nouns. So, discourse markers and lexical transfer were just responsible for code switching from a psycholinguistic perspective. Clyne (2003) considered lexical transfer as the items that are part of one language while do not belong the lexicon of the speaker of the other language. Instances of code switching related to the above mentioned paragraph are provided below:

(3) T: There are different types of nonvolatile memories. One nonvolatile is 'Floppy Disks'.

Ba hafezeye floppy disk ke ashna hastin. Hamin hafezehaye kuchak ba hajme kam o ghabele haml.

(You are all familiar with 'flash memory'...those small with low capacity and portable ones)

S: bale, kamelan (yes, completely).

In the above example, the word "Floppy Disk", which is considered to be prompted by "lexical transfer", led the teacher to code switch from English to Persian. In Persian, the same word is utilized to refer to the same thing. It shares the same idea of "lexical transfers that are not phonologically integrated (or integrated at a low level only) in the language of interaction" as is suggested by Riehl (2005, p.1947).

The following example is taken from the second class which explains the role of 'OK'.

Pas vozoohe tasvire manitor be te' dade pikselha bastegi dare.

(So the monitor resolution depends on the number of pixels). OK, did you know that pixel plays an important role in quality of a picture?

S: No.

$\mathrm{T}$ : So, listen to the discussion presented in the book. 
This example is the same as the discourse marker example given before.

\section{THE FUNCTIONS OF CODE SWITCHING}

Regarding code switching functions in EFL classes, the observation of the participants of the study revealed that there were 6 functions of code switching in both EFL contexts presented below.

\subsection{Providing Equivalent for the Key Words}

Teachers often provide the equivalent of the key words to get their ideas across to low proficient students. In Iran, since other majors other than English are of low English proficiency, the meanings of some words are given in Farsi. Sometimes even untranslatable words are faced by teachers and in order to continue the interaction, they code switch from English to Persian. An example from the data is provided here.

(5) T: Do you know the meaning of the word "Kinesiology" as appears in the text?

midunin maniye kalameye ' Kinesiology' ke dar matn umade chye?

S: yani taghlid kardan.

(It means imitating).

T: No...No. yani harakat shenasi.

(It means...)

This example explains the functionality of code switching in class settings. In this case, the teacher applies code switching in order to transfer the necessary knowledge for the students for lexical clarity. The teacher switches to native language in order to define meaning, and thereby stresses on the importance of the foreign language content for efficient comprehension. However, this function of code switching may have a harmful academic side effect. That is, a student who is aware that the teaching of the key words in the foreign language will be followed by a native language translation may not be interested enough to listen to the earlier instruction of those words in one language which leads to limited exposure to the foreign language (Mattson and Burenhult, 1999).

\subsection{Inspiring Students}

In order to improve students' motivation to learn English and keep them interested, instructors encourage students not to be afraid of making mistakes while involved in language teaching and learning processes. Instructors apply code switching from English to Persian to facilitate students' active engagement in the learning setting. The data below describes code switching practices for the purpose of encouraging students.

(6) T: Now, please change this sentence into passive voice "He has bought a DVD player".

S: Silence.

T: negaran nabashin, hatta age eshtebah ham mikonin say konin fekr konin o javab

bedin. (Don't worry if you think you're making mistakes just try to think and reply).

S: The DVD player have been bought.

T: ye kam bishtar fek konin. Negarane dadane javabe eshtebah nabashin. Ta eshtebah nakonin dorostesho yad nemigirin . (Think about it a little bit more, that's ok....don't worry about your mistakes.

(You don't learn the right forms unless you make mistakes).

The above example displays the concern of the teacher for having the learners in charge of their own learning while making errors. This reflects Corder's (1955) idea which highlights that when a learner makes an error, the most effective way to teach learners the correct form is by helping him/her discover it and test various hypotheses than by just providing him with the correct form. Teachers should give the learner the opportunity of finding the correct meaning and form. In the example above, the teacher utilized code switching to help learners with the opportunity of guessing and at the same time not being afraid of making mistakes.

\subsection{Expressing Humor}

In order to refresh students' minds and alleviate their tension, the instructors tended to code switch from English to Persian from time to time through creating humor. Examples from the data are presented here.

(7) T: Amir, answer this question: "What is your idea about being late?"

S: I think we have to be on time all the time.

T: Vaqean! Pas chera har jalase dir miai sare kelas? (Really! then why are you yourself late each session?)

S: laughing.

This sample can likewise be identified with the full of feeling capacity of code switching highlighted by Mattson and Burenhult (1999) that serves to express feelings. In this appreciation, code switching is connected in request to create an 
inclination of fellowship and cozy relations with the learners. Appropriately, it may prompt consoling language environment in which learners feel calm to impart and in the meantime appreciate learning.

\subsection{Explaining Next Assignments}

Another function of code switching observed in both classrooms was terminating each session when the instructors tended to switch to Persian for the sake of explaining the tasks students were required to do for the next session.

(8) T: Ok baraye jalase bad bayad dares jaded ro moroor konin, tamrinha sham anjam bedin va rooye mozoe matn fekr konin ta raje behesh sare kela bahs konim (For the next session, you are supposed to read the next lesson, do the exercises and think about the topic of the passage to discuss it in class.)

S: Ta che safheyee tamrin ha ro anjam bedim? (How many pages are we supposed to cover for the assignment?)

$\mathrm{T}$ : Ta safheye 64 (Up to page 64). Lazem nist tamrine gramere safheye 70 ro anjam bedin (You are not required to do the grammar exercise on page 70)

This sample is concerned with the teacher's endeavors to upgrade the learners' impression of classroom exercises. For this situation, he guarantees that learners have been decently educated of the following session assignments and would get prepared for the given undertakings.

\section{FINDINGS AND DISCUSSIONS}

This study tried to investigate code switching with regard to "trigger words" introduced by Clyne (1991). The results of the classes revealed varying frequency in the use of code switching in both classes. Moreover, the results of the study revealed the fact that among the four types of 'trigger words' just 'proper nouns' to a great extent and discourse marker 'OK' to a lesser extent were responsible for code switching in one setting while 'lexical transfer' and also the discourse marker 'OK' lead to code switch in another setting which might be attributed to classroom variables. With regard to the results dealing with the functions code switching served during interactions in the EFL classes, four functions were determined. They included providing equivalents for the key words, showing humor, inspiring learners, and explaining the required assignments.

There are various purposes behind code switching, as introduced by Crystal (1987). The principal of these is the idea that a speaker will be unable to express him/herself in one language so changes to the next to overcome the lack. Accordingly, the speaker may be activated into talking in the other language for some time. This sort of code switching has a tendency to happen when the speaker is disturbed, drained or diverted in some way. Furthermore, code switching usually happens when an individual wishes to express solidarity with a specific social gathering. Compatibility is created between the speaker and the audience when the audience reacts with a comparable switch. This kind of switching may additionally be utilized to prohibit others from discussions who don't talk the second language.

An illustration of such a circumstance may be two individuals in a lift in a language other than English. Others in the lift who don't talk the same language would be avoided from the discussion and a level of solace would exist amongst the speakers and every one of those who are present in the lift seems that are listening to their discussion but they understand nothing of what is said in the discussion.

The last explanation behind the switching conduct exhibited by Crystal (1987) is the change that happens when the speaker wishes to pass on his/her demeanor to the audience. Where monolingual speakers can impart these dispositions by method for variety in the level of convention in their discourse, bilingual speakers can pass on the same by code switching. Crystal (1987) proposes that where two bilingual speakers are accustoming to talk in a specific language, changing to the next is certain to make an embellishment. These ideas propose that code switching may be utilized as a sociolinguistic device by bilingual speakers.

The results of the study demonstrate that the amount of code switching is genuinely high in EFL classes and the genera effect is that learners are inclined to utilize L1 as a part of class much of the time. This may be brought about by their diminished inspiration to utilize the target language as a part of class owing to the way that they neither have preset objectives nor see any profits of taking a foreign language. Their presence in class is because of their obligation towards their families to go to class. Also, another essential point for them not to have inspiration is that they have no local speakers around in the school and no chances to travel abroad in the nearby future. Because of all these and numerous different concerns that the learners remember, they discover no method of reasoning to utilize the target language in class and utilize a lot of just L1 or a mixture of L1 and L2, particularly code switching. Essentially, the amount of code switching by educators is additionally most likely because of the previously stated reasons created by the learners and the simplicity to lead lessons with a mixture of two languages, as only opposed to the target language.

Student-initiated code switching is as much as what was expected because of the related involvements that learners don't attempt to practice English, rather they attempt to talk Farsi and continue so unless the teacher turns back to English. Teacher-initiated code switching was high for the few number of members. Learners are inclined to utilize code switching as a part of sentential level. At the end of the day, they might want to switch words as well as like to switch the entire sentence in a L2 discussion. This kind of code switching requires less exertion and capacity since it incorporates a piece of local language articulations. Thus, they even attempt to make the instructor talk Farsi.

Both teachers and the learners accept that the amounts of code switching are normal in lower levels, yet it ought to be diminished as the level gets higher. When learners have no clue about the target language, it is simpler for them to 
understand the target language utilizing cognates, the Contrastive Analysis Hypothesis (CAH) (Brown, 2007), or different correlations of the two languages so that they would likewise feel intrigued and, subsequently, motivated.

Since the level of the learners is low, instructors may feel expected to utilize a great deal of code switching to encourage understanding and draw in consideration. Moreover, when the low classroom inspiration is considered, instructors need to draw in their consideration regarding the lesson through L1 and L2 at generally. As in accordance with the theories, these capacities seemed high for educators. These outcomes accumulated from the perceptions were very parallel to the view of the instructors who trusted in utilizing code switching for pulling in consideration and explaining or checking. Then, it was gone before by their utilization of meta-language which was thought not to be a regular capacity in their eyes.

\section{CONCLUSIONS}

Teachers in both classes code switch when the learners were faced with low proficient students to help them comprehend much better. so, language proficiency plays a key role in this process. The second factor refers to the degree of the difficulty of the materials. The more difficult the materials, the more code switching. Moreover; code switching can be considered as a teaching strategy to help the students with low proficiency levels. This way, they can remove the barriers and understand the language efficiently.

One possible implication of those findings is that code switching practices are useful in dialect showing since teachers take the advantages of its utilization. An alternate ramification of those findings is that code switching ought to be endured or even advanced in educating learners at lower levels. In addition, one of the favorable circumstances for educators is the utilization of code switching in keeping up the coherence of correspondence in EFL settings.

From a psychological perspective, both EFL teachers felt agreeable and secure to change starting with one language then onto the next language when they were included at present language instructing. Be that as it may, this study needs to be replicated incorporating educators' perceptions on the utilization of code switching in other EFL connections and its suggestions may be seen by utilizing bigger and various corpuses of instructors and colleges.

\section{REFERENCES}

[1] Cheng, L., \& Butler, K. 1989. Code switching: a natural phenomenon versus language deficiency. World Englishes, 8 , 293-309.

[2] Cook, V. 2001. Second language learning and teaching (3rd Ed.). New York: Oxford University Press

[3] Cook, V. 2002. Portraits of the L2 User. Clevedon: Multilingual Matters

[4] Corder, S. P. 1967. The significance of learners 'errors. IRAL, 5, 161 - 169.

[5] Clyne, M. 1980. Triggering and language processing. Canadian Journal of Psychology, 34, $400-406$.

[6] Clyne, M. G. 1991. Community languages: the Australian experience. Cambridge: Cambridge University Press.

[7] Clyne, M. G. 2003. Dynamics of language contact. English and immigrant languages. Cambridge: Cambridge University Press.

[8] Crystal, D. 1987. The Cambridge encyclopedia of language. Cambridge: Cambridge University Press.

[9] Eldridge, J. 1996. Code-switching in a Turkish secondary school. ELT Journal, 50,4: 303-311

[10] Franceschini, R. 1998. Code - switching and the notion of code in linguistics: Proposals for a dual focus model. In Peter Auer (Ed.), Code - switching in conversation: Language, interaction, and identity, (pp. 51 - 75). NY: Routledge.

[11] Greggio, S. \& Gil, G. 2007. Teacher's and learner's use of code - switching in the English as a foreign language classroom: a qualitative study. Linguagem and Ensino, 10 (2) 371 - 393. Retrieved February, 20, 2013, from http://rle.ucpel.tche.br/php/edicoes/v10n2/02Greegio\%20e\%20Gil.pdf

[12] Gumperz, J. J. 1982. Discourse strategies. Cambridge: Cambridge University Press.

[13] Jacobson, R. 1983. Intersentential code switching: an educationally justifiable strategy. ERIC Document Reproduction Service No. ED231 221.

[14] Kachru, Y. 1989. Code-mixing, Style Repertoire and Language Variation: English in Hindu Poetic Creativity. World Englishes 8(3).

[15] Berthold, M., Mangubhai, F., \& Batorowicz, K. 1997. Bilingualism \& Multiculturalism: Study Book. Distance Education Centre, University of Southern Queensland: Toowoomba, QLD.

[16] Mattsson, A., \& Burenhult - Mattsson, N. 1999. Code - switching in second language teaching of French. Working Papers, 47, 59-72.

[17] Myers - Scotton, C.M. 1993. Social motivations for code switching: Evidence from Africa. Oxford: Oxford University Press. 


\section{ISSN 2321-1091}

[18] Nunan, D., \& Carter, R. 2001. The Cambridge guide to teaching English to speakers of other languages. Cambridge: Cambridge University Press.

[19] Riehl, C. M. 2005. Cognitive processes in bilinguals: impacts of mental processes and language awareness. Proceedings of the forth international symposium on bilingualism, 1945 - 1957. Somervile, MA: Cascadilla Press.

[20] Schweers, C.W.Jr. 1999. Using I1 in I2 classroom. The English Teaching Forum. 37 (2). Retrieved February, 10, 2013, from http://exchanges.state.gov.forum/vols/vol37/no2/p6.htm

[21] Skiba, Richard 1997. Code Switching as a Countenance of Language Interference, The Internet TESL Journal

[22] Tang, J. (2002). Using L1 in the English classroom. English Teaching Forum, 40 (1). Retrieved 7th February 2013 from http://exchanges.state.gov.forum/vols/vol40/no1/p36.pdf

[23] Vogt, H. (1954). Language Contacts. Word 10(2 - 3), 365 - 374.

[24] Yaqubi, B., \& Doquaruni, V. (2009). Examining the relationship between Iranian Non - native English teachers' use of communication strategies and context types within Iranian EFL classrooms. Iranian EFL Journal, 5, 46 - 92. 